Wars of Conquest and Independence Friedhelm Hentschel, Roland Hodler, Hadi Yektas June 2015 Discussion Paper no. 2015-16 


$\begin{array}{ll}\text { Editor: } & \text { Martina Flockerzi } \\ & \text { University of St.Gallen } \\ & \text { School of Economics and Political Science } \\ & \text { Department of Economics } \\ & \text { Bodanstrasse 8 } \\ & \text { CH-9000 St. Gallen } \\ & \text { Phone } \quad+41712242325 \\ & \text { Fax } \quad+41712243135 \\ & \text { Email seps@unisg.ch } \\ & \text { School of Economics and Political Science } \\ & \text { Department of Economics } \\ & \text { University of St.Gallen } \\ & \text { Bodanstrasse } 8 \\ \text { Publisher: } & \text { CH-9000 St. Gallen } \\ & \text { Phone +41 71 224 23 25 } \\ & \text { Fax }+41712243135 \\ & \text { http://www.seps.unisg.ch }\end{array}$




\title{
Wars of Conquest and Independence ${ }^{1}$
}

\author{
Friedhelm Hentschel ${ }^{2}$, Roland Hodler ${ }^{3}$ and Hadi Yektas ${ }^{4}$
}

Author's address:

\author{
Roland Hodler \\ University of St.Gallen \\ SIAW-HSG \\ Bodanstrasse 8 \\ $\mathrm{CH}-9000$ St. Gallen \\ Phone $\quad+41712242325$ \\ Fax $\quad+41712243135$ \\ Email roland.hodler@unisg.ch \\ Website www.rhodler.net
}

\footnotetext{
1 We would like to thank Michelle Garfinkel, Isa Hafalir, Magnus Hoffmann, Ozgur Kibris, Selçuk Özyurt, Mehmet Ali Ulubasoglu, and seminar participants at Antalya International University, Bilkent University, METU, and Sabanci University for helpful comments and discussions.

2 SIAW-HSG, University of St.Gallen. Email: friedhelm.hentschel@unisg.ch.

${ }^{3}$ Department of Economics and SIAW-HSG, University of St.Gallen; OxCarre, University of Oxford; and CESifo, Munich. Email: roland.hodler@unisg.ch.

${ }^{4}$ Department of Economics, Antalya International University. Email: hyektas@gmail.com.
} 


\begin{abstract}
Wars of conquest and wars of independence are characterized by an asymmetry in the payoff structure: The production of one party constitutes the winner's prize, while the production of the other party is not contested. We present and solve a model of warfare, which nests this asymmetric payoff structure as well as the standard symmetric payoff structure where the winner gets aggregate production. We use this model to discuss how equilibrium behavior and outcomes depend on resource endowments and military and production technologies in asymmetric wars; and to compare equilibrium behavior and outcomes in symmetric and asymmetric wars. Among others, we find that asymmetric wars are fought less intensively, and that defending countries in wars of conquest and secessionist groups in wars of independence have higher winning probabilities in such asymmetric wars than they would have in standard symmetric wars.
\end{abstract}

\title{
Keywords
}

Conflict; war; asymmetric contests.

\section{JEL Classification}

D74; H56. 


\section{Introduction}

The standard model of warfare goes back to Haavelmo (1954) and has been popularized by Garfinkel (1990), Grossman (1991), Hirshleifer (1991, 2001) and Skaperdas (1992). This model is based on the assumptions that a war takes place for exogenous reasons, that each party can choose how to allocate its resources to production and warfare, that the outcome of the war is probabilistic and determined by a contest success function, and that the winner gets aggregate production. ${ }^{1}$ This last assumption makes clear that this is a model designed for the study of wars with a symmetric payoff structure. The standard model is thus helpful to understand strategic behavior in civil wars for state control, or symmetric wars between neighboring countries. However it cannot inform us about strategic behavior in wars in which the involved parties face fundamentally different incentives due to an asymmetry in the payoff structure.

Wars of conquests and wars of independence are characterized by an asymmetry in the payoff structure: The production of one party constitutes the winner's prize, while the production of the other party is not contested. In wars of conquests, the attacking country can always keep its own production, and the countries fight only over the production (or resources) of the defending country. Similarly, in wars of independence, the central government and the secessionist region only fight over the production (or resources) in the secessionist region. The payoff structure in these types of wars is asymmetric even though the parties fight over the same prize. The reason for the asymmetry is that one party gets at worst its own production, while the other party gets at best its own production.

Wars of conquest were common, e.g., during the European colonization. The Spanish conquest of the Aztec empire is a prominent example. Both the Spaniards and the Aztecs knew perfectly well that they were only fighting over the Aztecs' production and resources, and not any Spanish production or resources. More recently, it was clear to the Vietnamese

\footnotetext{
${ }^{1}$ These standard models are discussed in more detail in Garfinkel and Skaperdas (2007, section 3.2). See Blattman and Miguel (2010), and again Garfinkel and Skaperdas (2007) for reviews of the literature on wars and conflicts; and Konrad (2009) for a review of the literature on contests more generally.
} 
communists fighting the U.S. army, and the Afghan mujahideen fighting the Soviets that they could at most win production or resources of their own territory, and no production or resources from the United States or the Soviet Union, respectively. Meanwhile the U.S. army and the Soviets knew that they would not lose any domestic production in case of defeat. Wars of independence are still common and have recently been fought by secessionist groups in, e.g., Aceh, Chechnya, Eritrea, Kosovo, Northern Sri Lanka, South Sudan, and Timor Leste. In all these conflicts, it was foreseeable from the onset that if the central government wins, it can control total production and resources; but if the secessionist group wins, it only gets production and resources of the newly independent region, while the defeated central government still gets production and resources from the rest of the country.

To the best of our knowledge, there exists no theory of wars that takes the asymmetry inherent in wars of conquest and wars of independence into account. We aim at filling this gap in the literature. We therefore introduce and solve a new workhorse model of warfare. In this model, like in the standard model, war takes place for exogenous reasons, each player can choose how to allocate its resources to production and warfare, and the outcome of the war is determined by a Tullock (1980) contest success function. Moreover, we allow for asymmetries in the players' military technologies, their production technologies, as well as their resource endowments. The key novelty of our workhorse model is its payoff structure which nests both the symmetric payoffs of the standard model as well as the asymmetric payoffs of wars of conquest and independence.

We use our workhorse model to better understand wars of conquest and independence. We do so in two ways. First, we analyze how changes in military and production technologies, and in resource endowments, impact on military spending and winning probabilities in asymmetric wars of conquest and independence. Second, we compare military spending and winning probabilities between the symmetric wars on which the literature has focused so far, and asymmetric wars of conquest and independence. We find, among others, that the winning probability of the attacking country in wars of conquest (or the central government 
in wars of independence) increases in its relative military technology, but decreases in its relative production technology. These comparative static results are similar as in symmetric wars, but changes in production technologies have different effects on military spending. While any change in production technologies increases military spending of the party that becomes relatively less productive in symmetric wars, the military spending of the two parties moves in the same direction in asymmetric wars. The two parties both fight less if the attacking country becomes relatively more productive, and they both fight more if the defending country becomes relatively more productive.

Another important difference between symmetric and asymmetric wars is that both parties fight less intensively in asymmetric wars. The difference in military spending between symmetric and asymmetric wars is larger for the party that would be the attacking country (or the central government) in an asymmetric war. This party faces considerably higher opportunity costs of military spending in an asymmetric war, in which it can keep its entire production with certainty, than in a symmetric war. Therefore, this party is less likely to win an asymmetric war than to win a symmetric war. This equilibrium outcome is consistent with the surprisingly frequent victories of secessionist groups and defending parties, including the Vietnamese communists and the Afghan mujahideen. Our model suggests that such victories of relatively small and weak secessionist groups and defending countries against larger and stronger opponents are no coincidence, but the result of the very different incentives faced by the conflicting parties in wars of conquest and independence.

Our paper is complementary to contributions that focus on other asymmetries between attacking and defending parties. Building on the standard models discussed above, Grossman and Kim (1995, 1996), and Bester and Konrad (2004) study models of conflict in which both parties can attack or defend, and in which there is a technological advantage for defensive activities (modeled by asymmetric contest success functions). In our model, as in wars of conquest and independence, there is a clear distinction between a party that can only attack and another party that can only defend. Moreover, we also allow for differences in military 
technology. Shubik and Weber (1981), Clark and Konrad (2007), Powell (2007a,b), and Arce et al. (2012) study models in which a defending party is vulnerable at several points, and needs to defend all these points successfully to win the battle, while the attacker wins if he can surmount the defender at one of these points. Wärneryd (2003) considers a contest in which only one party knows the prize. Similarly, in our model of asymmetric wars, only the defending country (or the secessionist group) knows the prize with certainty. But while the prize is drawn from a commonly known distribution in Wärneryd's model, it depends on the defending country's military spending and is therefore inversely related to this country's winning probability in our model.

Kolmar (2008) also presents a model in which two players can fight for the production of one of them. Despite this similarity, our paper differs in some important ways: First, while Kolmar focuses on the emergence of property rights, we focus on asymmetric warfare. Second, while Kolmar studies how results depend on the timing of the player's fighting choices, we study how results differ between symmetric and asymmetric payoff structures. Moreover, our model allows for rich comparative static analyses with respect to production and military technologies as well as resource endowments. ${ }^{2}$

The remainder of the paper is organized as follows: Section 2 introduces our workhorse model. Section 3 solves this model, and presents our novel results on asymmetric wars of conquest and independence. Section 4 concludes. The appendix contains all proofs.

\section{The Model}

There are two risk-neutral players, labeled 1 and $2 .{ }^{3}$ Player $i \in\{1,2\}$ is characterized by resource endowment $r_{i}>0$, military technology $\alpha_{i}>0$, and production technology

\footnotetext{
${ }^{2}$ Furthermore, Hillman and Riley (1989), and Nti (1999) study the effect of asymmetric valuations of contested prizes in rent-seeking contests. In our model of asymmetric wars, the attacking and the defending player also get different payoffs when winning, but the prize of winning is the same for both players: the defending player's production. Asymmetric valuations and contest structures are also studied in the literature on optimal contest design (see Franke et al., 2013, for a review).

${ }^{3}$ We adopt the convention that player 1 is a "he" and player 2 a "she".
} 
$\beta_{i}>0$, which are all common knowledge. For later use, we define player 1's relative resource endowment $r \equiv \frac{r_{1}}{r_{2}}$, his relative military technology $\alpha \equiv \frac{\alpha_{1}}{\alpha_{2}}$, his relative production technology $\beta \equiv \frac{\beta_{1}}{\beta_{2}}$, and his comparative advantage in warfare $\tau \equiv \frac{\alpha}{\beta}=\frac{\alpha_{1} / \beta_{1}}{\alpha_{2} / \beta_{2}}$.

The two players are at war for exogenous reasons. They simultaneously decide how to allocate their resources to production and warfare. ${ }^{4}$ Given resource endowment $r_{i}$, player $i$ chooses to allocate $b_{i} \in\left[0, r_{i}\right]$ to warfare, and $r_{i}-b_{i}$ to production. Player $i$ 's military power is then $\alpha_{i} b_{i}$, and his production $\beta_{i}\left(r_{i}-b_{i}\right)$. Nature determines the outcome of the war. The probability that player 1 wins is given by the ratio-form contest success function

$$
p=\left\{\begin{array}{lll}
\frac{\alpha_{1} b_{1}}{\alpha_{1} b_{1}+\alpha_{2} b_{2}}=\frac{\alpha b_{1}}{\alpha b_{1}+b_{2}} & \text { if } & b_{1}+b_{2}>0 \\
\frac{\alpha}{\alpha+1} & \text { if } & b_{1}=b_{2}=0
\end{array}\right.
$$

and the probability that player 2 wins by $1-p$.

The two players fight over the sum of player 2's entire production and share $x \in\{0,1\}$ of player 1's production. ${ }^{5}$ Hence, their expected payoffs are

$$
\begin{aligned}
& u_{1}\left(b_{1}, b_{2}\right)=(1-x) \beta_{1}\left(r_{1}-b_{1}\right)+p_{1}\left[x \beta_{1}\left(r_{1}-b_{1}\right)+\beta_{2}\left(r_{2}-b_{2}\right)\right] \\
& u_{2}\left(b_{1}, b_{2}\right)=\left(1-p_{1}\right)\left[x \beta_{1}\left(r_{1}-b_{1}\right)+\beta_{2}\left(r_{2}-b_{2}\right)\right] .
\end{aligned}
$$

This workhorse model nests the two models of conflict and warfare that are of interest to us. First, when $x=1$, then it boils down to the standard model of wars with symmetric payoffs. Second, when $x=0$, then it becomes a model of asymmetric wars of conquest and independence. In this case, player 1 gets aggregate production if he wins, while each player gets their own production if player 2 wins. Therefore, when thinking about wars of conquest, player 1 represents the attacking country, and player 2 the defending country. When thinking

\footnotetext{
${ }^{4}$ This timing assumption is innocuous. The results by Hoffmann and Rota-Graziosi (2012) and our payoff functions below imply that the equilibrium outcome would be the same if the players moved sequentially, independently of which player moved first.

${ }^{5}$ The equilibrium, characterized in Theorem 1 , would be the same if we assumed $x \in[0,1]$. We focus on the cases in which $x=0$ or $x=1$, because they represent the two payoff structures relevant to study wars of conquest and independence, and to compare these asymmetric wars with symmetric wars.
} 
about wars of independence, player 1 represents the central government, and player 2 the secessionist group.

The appropriate solution concept for this game is Nash equilibrium.

\section{Analysis}

In this section, we first illustrate the players' trade-offs and their best responses. We then derive the equilibrium of our workhorse model, and briefly present the equilibrium for the well-known case of wars with symmetric payoffs (characterized by $x=0$ ). We are then ready to study wars of conquest and independence with their asymmetric payoff structure (characterized by $x=1$ ). We present comparative static results for equilibrium behavior and outcomes in such asymmetric wars, and show how equilibrium behavior and outcomes differ between asymmetric and symmetric wars.

\subsection{The players' trade-offs and best responses}

The general trade-off that each player faces is that increasing military spending reduces production. To study the trade-offs of the two players in more detail, we insert the contest success function (1) into the expected payoff functions (2) and (3) and divide them by $\beta_{2}$, which is without loss of generality. We get

$$
\begin{aligned}
& \tilde{u}_{1}\left(b_{1}, b_{2}\right)=(1-x) \beta\left(r_{1}-b_{1}\right)+\frac{\alpha b_{1}}{\alpha b_{1}+b_{2}}\left[x \beta\left(r_{1}-b_{1}\right)+\left(r_{2}-b_{2}\right)\right] \\
& \tilde{u}_{2}\left(b_{1}, b_{2}\right)=\frac{b_{2}}{\alpha b_{1}+b_{2}}\left[x \beta\left(r_{1}-b_{1}\right)+\left(r_{2}-b_{2}\right)\right] .
\end{aligned}
$$

Player 1's trade-off of increasing military spending by one unit can be represented by

$$
\frac{\partial \tilde{u}_{1}\left(b_{1}, b_{2}\right)}{\partial b_{1}}=-\beta(1-x)-\beta x\left(\frac{\alpha b_{1}}{\alpha b_{1}+b_{2}}\right)+\frac{\alpha b_{2}}{\left(\alpha b_{1}+b_{2}\right)^{2}}\left[x \beta\left(r_{1}-b_{1}\right)+\left(r_{2}-b_{2}\right)\right] .
$$

The cost of increasing military spending is twofold for him: It implies lower uncontested 
production, $\beta(1-x)$, which is foregone with certainty, as well as lower contested production, $\beta x$, which is foregone if he is already a winner. He is already a winner with probability $\frac{\alpha b_{1}}{\alpha b_{1}+b_{2}}$. Thus, the sum of the first two terms in (6) represents player 1's expected marginal cost of increasing military spending. His benefit of increasing military spending is realized only if that slight increase turns him into a winner, which occurs with probability $\frac{\alpha b_{2}}{\left(\alpha b_{1}+b_{2}\right)^{2}}$. In this case, he gains the contested production $\left[x \beta\left(r_{1}-b_{1}\right)+\left(r_{2}-b_{2}\right)\right]$. Thus, the last term in (6) represents his expected marginal benefit of increasing military spending.

The second-order condition of player 1's utility maximization problem is satisfied, i.e., $\frac{\partial^{2} \tilde{u}_{1}\left(b_{1}, b_{2}\right)}{\partial b_{1}^{2}}<0$, whenever $b_{2}>0 .{ }^{6}$ Therefore, player 1 's best response to $b_{2}>0$ is the value of $b_{1}$ that solves the first-order condition $\frac{\partial \tilde{u}_{1}\left(b_{1}, b_{2}\right)}{\partial b_{1}}=0$ or, equivalently,

$$
\frac{1}{\tau}\left(\alpha b_{1}+b_{2}\right)^{2}-\left(\frac{x}{\tau}-1\right)\left(b_{2}\right)^{2}-\left(x \beta r_{1}+r_{2}\right) b_{2}=0
$$

if this value satisfies the resource constraint $b_{1} \in\left[0, r_{1}\right]$, and $b_{1}=r_{1}$ otherwise. $^{7}$

Player 2's trade-off of increasing military spending by one unit can be represented by

$$
\frac{\partial \tilde{u}_{2}\left(b_{1}, b_{2}\right)}{\partial b_{2}}=-\frac{b_{2}}{\alpha b_{1}+b_{2}}+\frac{\alpha b_{1}}{\left(\alpha b_{1}+b_{2}\right)^{2}}\left[\left(x \beta\left(r_{1}-b_{1}\right)+\left(r_{2}-b_{2}\right)\right] .\right.
$$

The cost of increasing military spending by one unit for player 2 is simply one unit of production that is foregone if she is already a winner, which is the case with probability $\frac{b_{2}}{\alpha b_{1}+b_{2}}$. Thus, the first term in (8) represents player 2's expected marginal cost of increasing military spending. Her benefit of increasing military spending is realized only if that slight increase will turn her into a winner, which occurs with probability $\frac{\alpha b_{1}}{\left(\alpha b_{1}+b_{2}\right)^{2}}$. In this case, she gains the contested production $\left[x \beta\left(r_{1}-b_{1}\right)+\left(r_{2}-b_{2}\right)\right]$. Thus, the second term in (8) represents her expected marginal benefit of increasing military spending.

\footnotetext{
${ }^{6}$ It holds that $\frac{\partial^{2} \tilde{u}_{1}\left(b_{1}, b_{2}\right)}{\partial b_{1}^{2}}=-2 \alpha \frac{b_{2}}{\left(b_{2}+\alpha b_{1}\right)^{3}}\left[\alpha\left(r_{2}-b_{2}\right)+x \beta\left(b_{2}+\alpha r_{1}\right)\right]$.

${ }^{7}$ It is a well-known problem in this type of conflict models that player 1's best response to $b_{2}=0$ is not well-defined (and vice versa). The reason is that he would want choose an infinitesimal positive amount in response to $b_{2}=0$ (and player 2 would want to do the same in response to $b_{1}=0$ ). This problem is however of minor importance as both players always have an incentive to choose $b_{i}>0$.
} 
The second-order condition of player 2's utility maximization maximization problem is satisfied, i.e., $\frac{\partial^{2} \tilde{u}_{2}\left(b_{1}, b_{2}\right)}{\partial b_{2}^{2}}<0$, whenever $b_{1}>0 .{ }^{8}$ Therefore, player 2's best response to $b_{1}>0$ is the value of $b_{2}$ that solves the first-order condition $\frac{\partial \tilde{u}_{2}\left(b_{1}, b_{2}\right)}{\partial b_{2}}=0$ or, equivalently,

$$
\left(\alpha b_{1}+b_{2}\right)^{2}+\left(\frac{x}{\tau}-1\right)\left(\alpha b_{1}\right)^{2}-\left(x \beta r_{1}+r_{2}\right) \alpha b_{1}=0
$$

if this value satisfies the resource constraint $b_{2} \in\left[0, r_{2}\right]$, and $b_{2}=r_{2}$ otherwise.

\subsection{Equilibrium}

Our workhorse model has always a unique Nash equilibrium. This equilibrium can take various forms depending on parameter values. There can exist an interior equilibrium with equilibrium strategies $b_{1}^{*} \in\left(0, r_{1}\right)$ and $b_{2}^{*} \in\left(0, r_{2}\right)$ determined by the values of $b_{1}$ and $b_{2}$ that solve (7) and (9) simultaneously. In addition, there can exist a corner equilibrium in which $b_{1}^{*}=r_{1}$, while $b_{2}^{*} \in\left(0, r_{2}\right)$ is determined by the value of $b_{2}$ that solves (9); or a corner equilibrium in which $b_{2}^{*}=r_{2}$, while $b_{1}^{*} \in\left(0, r_{1}\right)$ is determined by the value of $b_{1}$ that solves $(7)$. There can however not exist an equilibrium in which both players invest all their resources $r_{i}$ into warfare. The reason is that both players' expected payoff would be zero, so that each player would have an incentive to deviate unilaterally, and to allocate some resources to production instead.

The following thresholds are useful to partition the parameter space:

$$
\begin{aligned}
& \underline{r} \equiv \frac{1}{\beta}\left[\frac{2(x-\tau)}{1-\frac{2 \tau+1-x}{\sqrt{4 \tau+(1-x)^{2}}}}-x\right]^{-1} \\
& \bar{r} \equiv \frac{1}{\beta}\left[\frac{2(x-\tau)}{\left(\frac{1+x}{\sqrt{4 \tau+(1-x)^{2}}}-1\right) \tau x}-\frac{1}{x}\right] .
\end{aligned}
$$

Observe first that $\bar{r}>\underline{r}>0$; and second that $\underline{r}$ and $\bar{r}$ are not defined for $x=\tau$, but

${ }^{8}$ It holds that $\frac{\partial^{2} \tilde{u}_{2}\left(b_{1}, b_{2}\right)}{\partial b_{2}^{2}}=-2 \alpha \frac{b_{1}}{\left(b_{2}+\alpha b_{1}\right)^{3}}\left[r_{2}+\alpha b_{1}+\left(r_{1}-b_{1}\right) x \beta\right]$. 
$\lim _{x \rightarrow \tau} \underline{r}=\frac{\tau}{2 \alpha+\beta}$ and $\lim _{x \rightarrow \tau} \bar{r}=\frac{\alpha^{2}+\alpha \beta+\beta^{2}}{\alpha^{2} \beta}$.

Theorem 1 There exists a unique Nash equilibrium, which takes one of following forms:

1. Given $x \neq \tau$ and $r \in(\underline{r}, \bar{r})$, equilibrium strategies are

$$
\begin{aligned}
& b_{1}^{*}=\frac{x \beta r_{1}+r_{2}}{2 \alpha\left(1-\frac{x}{\tau}\right)}\left[\frac{2 \tau+1-x}{\sqrt{4 \tau+(1-x)^{2}}}-1\right] \\
& b_{2}^{*}=\frac{x \beta r_{1}+r_{2}}{2\left(1-\frac{x}{\tau}\right)}\left[1-\frac{(1+x)}{\sqrt{4 \tau+(1-x)^{2}}}\right] .
\end{aligned}
$$

Given $x=\tau$ and $r \in\left(\lim _{x \rightarrow \tau} \underline{r}, \lim _{x \rightarrow \tau} \bar{r}\right)$, equilibrium strategies are

$$
\begin{aligned}
& b_{1}^{*}=\frac{\alpha}{(\beta+\alpha)^{2}}\left(\alpha r_{1}+r_{2}\right) \\
& b_{2}^{*}=\frac{\beta \alpha}{(\beta+\alpha)^{2}}\left(\alpha r_{1}+r_{2}\right) .
\end{aligned}
$$

2. Given either $x \neq \tau$ and $r \leq \underline{r}$, or $x=\tau$ and $r \leq \lim _{x \rightarrow \tau} \underline{r}$, equilibrium strategies are $b_{1}^{*}=r_{1}$ and

$$
b_{2}^{*}=\sqrt{\alpha r_{1}\left(\alpha r_{1}+r_{2}\right)}-\alpha r_{1}
$$

3. Given either $x \neq \tau$ and $r \geq \bar{r}$, or $x=\tau$ and $r \geq \lim _{x \rightarrow \tau} \bar{r}$, equilibrium strategies are $b_{2}^{*}=r_{2}$ and

$$
b_{1}^{*}=\frac{1}{\alpha}\left[\sqrt{x r_{2}\left(\alpha r_{1}+r_{2}\right)}-r_{2}\right]
$$

Observe that strategies (12) and (13) converge to strategies (14) and (15), respectively, as $x$ goes to $\tau$. The equilibrium strategies $b_{1}^{*}$ and $b_{2}^{*}$ are thus continuous in $x$ and $\tau$.

\subsection{Symmetric wars}

Our workhorse model boils down to the standard model of warfare with symmetric payoffs when $x=1$. For later use, we now characterize equilibrium behavior in this special case. The 
equilibrium strategies $b_{1}^{*}$ and $b_{2}^{*}$ follow directly from Theorem 1, and player 1's equilibrium winning probability can then be derived as $p^{*}=\frac{\alpha b_{1}^{*}}{\alpha b_{1}^{*}+b_{2}^{*}}$.

Corollary 1 Suppose $x=1$. Then the equilibrium strategies are

$$
\begin{aligned}
& b_{1}^{*}= \begin{cases}\frac{r_{2}}{\alpha}(\sqrt{\alpha r+1}-1) & \text { if } r>\left.\bar{r}\right|_{x=1} \\
\frac{1}{\alpha}\left(\frac{\beta r_{1}+r_{2}}{2} \frac{\tau}{\sqrt{\tau}+1}\right) & \text { if } r \in\left(\left.\underline{r}\right|_{x=1},\left.\bar{r}\right|_{x=1}\right) \\
r_{1} & \text { if } r<\left.\underline{r}\right|_{x=1},\end{cases} \\
& b_{2}^{*}= \begin{cases}r_{2} & \text { if } r>\left.\bar{r}\right|_{x=1} \\
\frac{\beta r_{1}+r_{2}}{2} \frac{\sqrt{\tau}}{\sqrt{\tau}+1} & \text { if } r \in\left(\left.\underline{r}\right|_{x=1},\left.\bar{r}\right|_{x=1}\right) \\
\alpha r_{1}\left[\sqrt{\left(1+\frac{1}{\alpha r}\right)}-1\right] & \text { if } r<\left.\underline{r}\right|_{x=1},\end{cases}
\end{aligned}
$$

where $\left.\underline{r}\right|_{x=1}=\frac{1}{\beta(2 \sqrt{\tau}+1)}$ and $\left.\bar{r}\right|_{x=1}=\frac{1}{\beta}\left(\frac{2}{\sqrt{\tau}}+1\right)$, and player 1's winning probability is

$$
p^{*}= \begin{cases}1-\frac{1}{\sqrt{\alpha r+1}} & \text { if } r>\left.\bar{r}\right|_{x=1} \\ \frac{\sqrt{\tau}}{\sqrt{\tau}+1} & \text { if } r \in\left(\left.\underline{r}\right|_{x=1},\left.\bar{r}\right|_{x=1}\right) \\ \frac{1}{\sqrt{1+\frac{1}{\alpha r}}} & \text { if } r<\left.\underline{r}\right|_{x=1} .\end{cases}
$$

Given that the standard model with symmetric payoffs is well studied in the literature, we refrain from presenting comparative static results here. There is however one result worth mentioning (see also Garfinkel and Skaperdas, 2007): In the interior equilibrium, where $r \in\left(\left.\underline{r}\right|_{x=1},\left.\bar{r}\right|_{x=1}\right)$, an increase in player 1's relative production technology $\beta$ leads to lower $b_{1}^{*}$, higher $b_{2}^{*}$ and, consequently, lower $p^{*}$. To illustrate this result, suppose that one player gets more productive. This player reduces military spending because the productivity increase leads to a proportional increase in his cost of increasing military spending, but a less pronounced increase of the winner's prize, which also depends on his opponent's production. The opponent increases her military spending because the winner's prize increases while her cost of increasing military spending remains unchanged. Therefore, whenever a player gets more productive, he becomes less likely to win a symmetric war. 


\subsection{Asymmetric wars of conquest and independence}

We now focus on the special case when $x=0$ to study wars of conquest and independence. Remember that in this case player 1 represents the attacking country or the central government, and player 2 the defending country or the secessionist group, respectively. As before, the equilibrium strategies $b_{1}^{*}$ and $b_{2}^{*}$ follow directly from Theorem 1 , which again allow determining player 1's equilibrium winning probability $p^{*}$.

Corollary 2 Suppose $x=0$. Then the equilibrium strategies are

$$
\begin{aligned}
& b_{1}^{*}= \begin{cases}\frac{r_{2}}{2 \alpha}\left(\frac{2 \tau+1}{\sqrt{4 \tau+1}}-1\right) & \text { if } r>\left.\underline{r}\right|_{x=0} \\
r_{1} & \text { if } r<\left.\underline{r}\right|_{x=0},\end{cases} \\
& b_{2}^{*}= \begin{cases}\frac{r_{2}}{2}\left(1-\frac{1}{\sqrt{4 \tau+1}}\right) & \text { if } r>\left.\underline{r}\right|_{x=0} \\
\alpha r_{1}\left(\sqrt{1+\frac{1}{\alpha r}}-1\right) & \text { if } r<\left.\underline{r}\right|_{x=0},\end{cases}
\end{aligned}
$$

where $\left.\underline{r}\right|_{x=0}=\frac{1}{2 \alpha}\left(\frac{2 \tau+1}{\sqrt{4 \tau+1}}-1\right)$, and player 1's winning probability is

$$
p^{*}=\left\{\begin{array}{lll}
1-\frac{\sqrt{4 \tau+1}-1}{2 \tau} & \text { if } & r>\left.\underline{r}\right|_{x=0} \\
\frac{1}{\sqrt{1+\frac{1}{\alpha r}}} & \text { if } & r<\left.\underline{r}\right|_{x=0} .
\end{array}\right.
$$

Corollary 2 shows that player 2 never allocates all her resources to warfare in equilibrium, i.e., $b_{2}^{*}<r_{2}$ for all parameter values. The reason is that the winner's prize becomes zero when she allocates all resources to warfare. Therefore, she is always better off when devoting at least some resources to production to ensure that she gets a positive prize when winning.

We now turn to the comparative statics and discuss how changes in the relative technologies $\alpha$ and $\beta$, and the resource endowments $r_{1}$ and $r_{2}$ impact on equilibrium behavior and winning probabilities. Thereby we need to look separately at the interior equilibrium (where $r>\left.\underline{r}\right|_{x=0}$ ) and the corner equilibrium (where $r<\left.\underline{r}\right|_{x=0}$ ), in which player 1 allocates all his resources to warfare. We first look at the effects of changes in military technologies: 
Proposition 1 Suppose $x=0$. Then an increase in player 1's relative military technology $\alpha$ has always a positive effect on $b_{2}^{*}$ and $p^{*}$, while it has an ambiguous effect on $b_{1}^{*}$ if $r>\left.\underline{r}\right|_{x=0}$, but no effect on $b_{1}^{*}$ if $r<\left.\underline{r}\right|_{x=0}$.

Whenever a player's military technology $\alpha_{i}$ improves, the main direct effect is an increase in his or her winning probability. Of course, any change in the relative military technology $\alpha$ may also change incentives, thereby leading to behavioral responses, i.e., changes in equilibrium strategies. Nevertheless, an increase in player 1's relative military technology $\alpha$ increases his winning probability $p^{*}$ (which obviously implies that an increase in $\alpha_{2}$ increases player 2's winning probability $1-p^{*}$ ). If player 1 is not resource constrained, better military technology $\alpha$ increases both his cost and his benefit of increasing military spending. The benefit increases because higher military spending now has a stronger positive effect on his winning probability, and the cost increases because he is already winning the war with higher probability. As a result of these countervailing effects, better military technology has an ambiguous effect on his military spending. ${ }^{9}$ Trivially, a small change in military technologies has no effect on his military spending if he allocates all resources to warfare anyway. Player 2's behavioral response is always to increase her military spending if $\alpha$ increases, i.e., if her military technology gets comparatively weaker. The reason is that the cost of increasing military spending, which corresponds to the probability of already being the winner, decreases more strongly than her benefit of increasing military spending.

We now turn to the effects of changes in the players' production technologies:

Proposition 2 Suppose $x=0$. Then an increase in player 1's relative production technology $\beta$ has a negative effect on $b_{1}^{*}, b_{2}^{*}$ and $p^{*}$ if $r>\left.\underline{r}\right|_{x=0}$. It has no effect on $b_{1}^{*}, b_{2}^{*}$ and $p^{*}$ if $r<\left.\underline{r}\right|_{x=0}$.

An increase in player 1's relative production technology $\beta$ raises his opportunity costs of military spending, which corresponds to his foregone production, relative to the winner's

\footnotetext{
${ }^{9}$ As shown in the proof of Proposition 1, the net effect is positive unless player 1's comparative advantage in warfare $\tau$ is sufficiently large. The reason is that he is winning with high probability anyway if $\tau$ is large, such that he optimally reduces military spending in response to a further increase in $\alpha$ and $\tau$.
} 
prize, which corresponds to player 2's production. Player 1 therefore optimally reduces his military spending $b_{1}^{*}$ in response to an increase in $\beta$. Further, such an increase leads to proportional changes in player 2's cost and benefit of increasing military spending, such that her best response to player 1's military spending remains unchanged. Due to the reduction of $b_{1}^{*}$, player 2 however reduces her military spending $b_{2}^{*}$ in equilibrium. But as her reduction in military spending is less pronounced, she becomes more likely to win, and player 1's winning probability $p^{*}$ decreases. Hence, whenever a player gets more productive, he becomes less likely to win the war.

As discussed in Section 3.3, a player whose production technology improves becomes less likely to win a symmetric war. As just seen, this prominent result from the standard model also holds in asymmetric wars. The underlying mechanism is however different. Figure 1 illustrates this difference.

Figure 1 around here

In the symmetric case, the player who gets relatively more productive reduces military spending while the opponent increases military spending. But in the asymmetric case, any change in production technologies has the same qualitative effects on both players' military spending. If player 1, i.e., the attacking country or the central government, gets relatively more productive, both players reduce their military spending. But if player 2, i.e., the defending country or the secessionist group, gets relatively more productive both players increase their military spending. The same result with respect to the players' winning probabilities arises because player 2's behavioral response to changes in the relative production technology is less pronounced than player 1's response.

Proposition 2 further shows that production technologies have no effect on equilibrium behavior if player 1 does not produce anyway. At first, it may seem surprising that player 2 does not respond to changes in the production technologies $\beta_{1}$ and $\beta_{2}$ in this case. However, a change in $\beta_{1}$ is inconsequential to her because she does not get any of player 1's production anyway, and a change in $\beta_{2}$ does not affect her behavior because it leads to proportional 
changes in her cost and her benefit of increasing military spending.

We finally look how resource endowments affect military spending and winning probabilities:

Proposition 3 Suppose $x=0$. Then, if $r>\left.\underline{r}\right|_{x=0}$, an increase in player 1's resource endowment $r_{1}$ has no effect on $b_{1}^{*}, b_{2}^{*}$ and $p^{*}$, while an increase in player 2's resource endowment $r_{2}$ proportionally increases $b_{1}^{*}$ and $b_{2}^{*}$, thus having no effect on $p^{*}$. If $r<\left.\underline{r}\right|_{x=0}$, an increase in $r_{1}$ has a positive effect on $b_{1}^{*}, b_{2}^{*}$ and $p^{*}$, while an increase in $r_{2}$ has no effect on $b_{1}^{*}$, but a positive effect on $b_{2}^{*}$ and a negative effect on $p^{*}$.

The equilibrium behavior of both players depends on player 2's resource endowment $r_{2}$, but not on player 1's resource endowment $r_{1}$ as long as none of the players is resource constrained. Looking at (6) and (8) suggests that the players do not respond to a change in $r_{1}$ because such a change affects neither their benefits, nor their costs of increasing military spending when $x=0$. An increase in $r_{2}$ however increases both players' benefits of increasing military spending, without affecting their costs. Hence, they respond by increasing $b_{1}^{*}$ and $b_{2}^{*}$. More intuitively, when player 2 gets additional resources, she finds it optimal to increase both production and military spending. The increase in her production in turn motivates player 1 to increase his military spending as well. The increases in $b_{1}^{*}$ and $b_{2}^{*}$ are proportional to one another, so that the winning probability $p^{*}$ does not change.

Obviously, player 1's military spending $b_{1}^{*}$ depends exclusively on his own resources $r_{1}$

if he is resource constrained. In this case, player 2 also increases military spending $b_{2}^{*}$ in response to an increase in $r_{1}$ (and the associated increase in $b_{1}^{*}$ ), but less than player 1 does. Player 1 becomes therefore more likely to win the war.

\subsection{Comparison of asymmetric and symmetric wars}

We now compare the players' equilibrium behavior and the equilibrium outcome between wars of conquest and independence with their asymmetric payoff structure $(x=0)$, and wars with a standard symmetric payoff structure $(x=1)$. 
Observe that $\left.\underline{r}\right|_{x=0}<\left.\underline{r}\right|_{x=1}<\left.\bar{r}\right|_{x=1}$. It therefore follows from Corollaries 1 and 2 that the players' military spending and, consequently, their winning probabilities are the same in asymmetric and symmetric wars if $r<\left.\underline{r}\right|_{x=0}$, i.e., if player 1 allocates all his resources to warfare in both types of war.

In the remainder of this section we restrict our attention to the more interesting case in which $r>\left.\underline{r}\right|_{x=0}$. We first compare the players' military spending $b_{1}^{*}$ and $b_{2}^{*}$ :

Proposition 4 Given $r>\left.\underline{r}\right|_{x=0}, b_{1}^{*}$ and $b_{2}^{*}$ are both lower in asymmetric wars $(x=0)$ than in symmetric wars $(x=1)$ for all values of $\alpha, \beta, r_{1}$ and $r_{2}$.

Hence, attacking and defending countries in wars of conquest, and central governments and secessionist groups in wars of independence all allocate less resources to warfare than they would in symmetric wars characterized by the same resource endowments and the same relative production and military technologies. The attacking countries and central governments are aware that they can keep their own production anyway, which raises their cost of increasing military spending. Moreover, their benefit of increasing military spending decreases as the prize is only composed of the opponent's production rather than aggregate production. Similarly, the defending countries and secessionist groups are also aware that they cannot possibly grab any production from their opponent, which lowers their benefit of increasing military spending as well.

It directly follows from Propositions 4 that wars of conquest and independence involve lower aggregate military spending $\left(b_{1}^{*}+b_{2}^{*}\right)$ than symmetric wars. Moreover, it follows:

Corollary 3 Given $r>\left.\underline{r}\right|_{x=0}$, aggregate production $\left[\beta_{1}\left(r_{1}-b_{1}^{*}\right)+\beta_{2}\left(r_{2}-b_{2}^{*}\right)\right]$ is higher in asymmetric wars $(x=0)$ than in symmetric wars $(x=1)$ for all values of $\alpha, \beta, r_{1}$ and $r_{2}$.

Hence, all else equal, wars of conquest and independence cause lower losses of production than symmetric wars.

We next compare the players' winning probabilities: 
Proposition 5 Given $r>\left.\underline{r}\right|_{x=0}$, player 1's probability of winning $p^{*}$ is lower in asymmetric wars $(x=0)$ than in symmetric wars $(x=1)$ for all values of $\alpha, \beta, r_{1}$ and $r_{2}$.

Hence, attacking countries in wars of conquest and central governments in wars of independence are less likely to win than they would be in symmetric wars characterized by the same resource endowments and the same relative production and military technologies. The opposite must obviously be true for defending countries and secessionist groups. Mechanically, the reason must be that the difference in military spending between wars with symmetric and asymmetric payoff structures is more pronounced for player 1 than for player 2 . The reason for this difference in differences is that while both players have lower benefits of increasing military spending in asymmetric wars than in symmetric wars, player 1 has also much higher costs of increasing military spending in asymmetric wars in which he can keep his entire production.

We finally compare the players' expected utility. Both players are indifferent between the two types of war if player 1's resource endowment is so poor that he allocates all his resources to warfare in any type of war, i.e., if $r<\left.\underline{r}\right|_{x=0}$. In this case the winner's prize is anyway just player 2's production. We now focus on the more interesting case in which $r>\left.\underline{r}\right|_{x=0}$. For that purpose we define $\rho \equiv \frac{1}{\beta}\left(2 \frac{\sqrt{\tau}+1}{\sqrt{4 \tau+1}}-1\right)$. Observe that $\rho \in\left(\left.\underline{r}\right|_{x=0},\left.\bar{r}\right|_{x=1}\right)$.

Proposition 6 Given $r>\left.\underline{r}\right|_{x=0}$, player 1 prefers asymmetric wars $(x=0)$ over symmetric wars $(x=1)$; and player 2 prefers symmetric wars if $r>\rho$, and asymmetric wars if $r<\rho$.

From player 1's perspective there are two aspects that make asymmetric wars more attractive than symmetric wars. First, when loosing, he can still keep his own production in asymmetric wars, but not in symmetric wars. Second, when winning, his payoff is aggregate production in both types of wars, but aggregate production is higher in asymmetric wars (see Corollary 3). Player 1 is thus unambiguously better off in asymmetric wars.

From player 2's perspective there is a trade-off: Asymmetric wars have the advantage that she wins with higher probability despite allocating fewer resources to warfare. Symmetric 
wars have the advantage that she gets not only her own, but also the opponent's production when winning. This advantage of symmetric wars is increasing in player 1's relative resource endowment $r$. Therefore, player 2 is better off in symmetric wars if $r$ is relatively high, and in asymmetric wars if $r$ is relatively low.

In our model and in many real-world examples, the players or parties cannot choose what type of war they fight. However, Proposition 6 can shed some light on the type of war that parties might choose if they had a choice. We have two situations in mind. First, in the context of interstate wars, suppose a country could commit never to counter-attack an attacking country, not even after having successfully defeated it. Such a commitment might be possible by signing multilateral treaties, or by holding weapons that serve only defensive purposes. Proposition 6 predicts that the country would want to commit if and only if it were relatively well-endowed with factors of production. In this case, the benefit of having a less intensive conflict and a higher winning probability would outweigh the cost of forgoing the chance of winning the opponent's production.

Second, in the context of civil wars, an ethnic group that is currently out of power and lives in a border area might have the choice between fighting for independence or fighting for power over the entire country. Our model predicts that this ethnic group would choose to fight for independence if it were relatively well-endowed with factors of production, and for central government power otherwise. The reason is again that the benefit of fighting for independence would be much larger if its own production tended to be substantial compared to the opponent's production.

\section{Conclusions}

Wars of conquest were common, and wars of independence are still common. These wars are however not well understood. The standard model of warfare has a symmetric payoff structure, while wars of conquest and independence have an important asymmetry in the payoff 
structure: The production of one party constitutes the winner's prize, while the production of the other party is not contested. In this paper, we have presented the first model of warfare that incorporates this crucial asymmetry in the payoff structure of wars of conquest and independence. We have used this model to study the determinants of equilibrium behavior and outcomes in such asymmetric wars, and to compare equilibrium behavior and outcomes between symmetric and asymmetric wars.

We find that the winning probability of the attacking country in wars of conquest (or the central government in wars of independence) increases in its relative military technology, but decreases in its relative production technology. These comparative static results are similar as in symmetric wars, but the underlying mechanisms differ. In particular, both countries increase their military spending if the attacking country becomes more productive, but reduce their military spending if the defending country becomes more productive. Another important finding is that both parties choose lower military spending in asymmetric wars than in symmetric wars. This difference is larger for the party that would be the attacking country (or the central government) in an asymmetric war. This party is thus less likely to win an asymmetric war than it would be to win a symmetric war. This result may explain why supposedly relatively weak defending countries and secessionist groups often win against larger and stronger opponents.

We hope that this first theoretical model of wars of conquest and independence will encourage further research that helps to improve our understanding of these wars. 


\section{Appendix: Proofs}

Proof of Theorem 1: We prove parts 1-3 separately.

Part 1: We look for an interior solution $\left(b_{1}^{*}, b_{2}^{*}\right)$ that simultaneously solves (7) and (9). Adding (9) to (7) and rearranging yields

$$
\left(1+\frac{1}{\tau}\right)\left(\alpha b_{1}^{*}+b_{2}^{*}\right)^{2}+\left(\frac{x}{\tau}-1\right)\left(\alpha b_{1}^{*}+b_{2}^{*}\right)\left(\alpha b_{1}^{*}-b_{2}^{*}\right)-\left(x \beta r_{1}+r_{2}\right)\left(\alpha b_{1}^{*}+b_{2}^{*}\right)=0
$$

We can divide this equation by $\alpha b_{1}^{*}+b_{2}^{*}>0$ to obtain

$$
\left(1+\frac{1}{\tau}\right)\left(\alpha b_{1}^{*}+b_{2}^{*}\right)+\left(\frac{x}{\tau}-1\right)\left(\alpha b_{1}^{*}-b_{2}^{*}\right)-\left(x \beta r_{1}+r_{2}\right)=0
$$

Solving this equation for $b_{2}^{*}$ yields

$$
b_{2}^{*}=\frac{\left(x \beta r_{1}+r_{2}\right) \tau}{2 \tau+1-x}-\frac{1+x}{2 \tau+1-x}\left(\alpha b_{1}^{*}\right)
$$

Substituting this equation into (9) yields

$$
\left[\alpha b_{1}^{*}+\frac{\left(x \beta r_{1}+r_{2}\right) \tau}{2 \tau+1-x}-\frac{1+x}{2 \tau+1-x}\left(\alpha b_{1}^{*}\right)\right]^{2}+\left(\frac{x}{\tau}-1\right)\left(\alpha b_{1}^{*}\right)^{2}-\left(x \beta r_{1}+r_{2}\right) \alpha b_{1}^{*}=0
$$

which can be simplified as a quadratic equation of the form

$$
\left(\frac{x}{\tau}-1\right)\left(\alpha b_{1}^{*}\right)^{2}-\left(x \beta r_{1}+r_{2}\right)\left(\alpha b_{1}^{*}\right)+\frac{\left[\tau\left(x \beta r_{1}+r_{2}\right)\right]^{2}}{(1-x)^{2}+4 \tau}=0
$$

with discriminant

$$
\Delta=\left(x \beta r_{1}+r_{2}\right)^{2}-4\left(\frac{x}{\tau}-1\right) \frac{\left[\tau\left(x \beta r_{1}+r_{2}\right)\right]^{2}}{(1-x)^{2}+4 \tau}=\left(x \beta r_{1}+r_{2}\right)^{2} \Omega>0
$$

where

$$
\Omega=\frac{[\beta(1-x)+2 \alpha]^{2}}{\beta^{2}(1-x)^{2}+4 \alpha \beta} .
$$


Thus, equation (22) has two roots of the form

$$
\alpha b_{1}^{*}=\frac{x \beta r_{1}+r_{2}}{2\left(\frac{x}{\tau}-1\right)}(1 \mp \sqrt{\Omega}) .
$$

Note that (25) is defined only if $x \neq \tau$. If $x<\tau$, then the denominator in the first multiplicand in $(25)$ is negative and $\sqrt{\Omega}>1$, such that there is a unique positive root:

$$
\alpha b_{1}^{*}=\frac{x \beta r_{1}+r_{2}}{2\left(\frac{x}{\tau}-1\right)}(1-\sqrt{\Omega})
$$

If $x>\tau$, then the denominator in the first multiplicand in $(25)$ is positive and $\sqrt{\Omega}<1$, such that there is an unique feasible positive root, which is again of the form (26). (The other candidate root is not feasible as it would imply $b_{2}^{*}<0$.) The equilibrium strategy $(12)$ follows from (26) and the definition of $\Omega$. Moreover, substituting (12) into (20) yields player 2's equilibrium strategy (13).

Now consider the case when $x=\tau$. In this case, (19) reduces to

$$
\frac{1+\tau}{\tau}\left(\alpha b_{1}^{*}+b_{2}^{*}\right)-\left(\alpha r_{1}+r_{2}\right)=0
$$

and yields

$$
b_{2}^{*}=\frac{\left(\alpha r_{1}+r_{2}\right) \tau}{1+\tau}-\alpha b_{1}^{*}
$$

Substituting it into (9) and solving for $b_{1}^{*}$ gives player 1's equilibrium strategy (14). Substituting the latter back into (28) yields player 2's equilibrium strategy (15).

It remains to show that the equilibrium is characterized by (12) and (13) if and only if $r \in(\underline{r}, \bar{r})$ when $x \neq \tau$; and by (14) and (15) if and only if $r \in\left(\lim _{x \rightarrow \tau} \underline{r}, \lim _{x \rightarrow \tau} \bar{r}\right)$ when $x=\tau$.

Consider first the case when $x \neq \tau$. Using (12) the necessary condition $b_{1}^{*}<r_{1}$ can be 
written as

$$
\frac{x \beta+\frac{r_{2}}{r_{1}}}{2 \beta(x-\tau)}\left[1-\frac{2 \tau+1-x}{\sqrt{4 \tau+(1-x)^{2}}}\right]<1 .
$$

Given that $(x-\tau)$ and $\left[1-\frac{2 \tau+1-x}{\sqrt{4 \tau+(1-x)^{2}}}\right]$ must have the same signs, we can rewrite this inequality as

$$
\frac{r_{2}}{r_{1}}<\beta\left[\frac{2(x-\tau)}{1-\frac{2 \tau+1-x}{\sqrt{4 \tau+(1-x)^{2}}}}-x\right] .
$$

Because the term in the square brackets is positive for all $\tau>0$ and $x \in[0,1]$, this inequality is equivalent to $r>\underline{r}$.

Similarly, using (13) the necessary condition $b_{2}^{*}<r_{2}$ can be written as

$$
\frac{x \beta r+1}{\frac{2}{\tau}(x-\tau)}\left[\frac{1+x}{\sqrt{4 \tau+(1-x)^{2}}}-1\right]<1 .
$$

Note again that $(x-\tau)$ and $\left[\frac{1+x}{\sqrt{4 \tau+(1-x)^{2}}}-1\right]$ have the same signs, such that this inequality can be rewritten as $r<\bar{r}$. Thus, when $x \neq \tau$, conditions $b_{1}^{*}<r_{1}$ and $b_{2}^{*}<r_{2}$ are jointly satisfied if and only if $r \in(\underline{r}, \bar{r})$.

Consider now the case when $x=\tau$ : It follows from (14) and (15) that conditions $b_{1}^{*}<r_{1}$ and $b_{2}^{*}<r_{2}$ are jointly satisfied if $\frac{\alpha}{(\alpha+\beta)^{2}}\left(\alpha r_{1}+r_{2}\right)<r_{1}$ and $\frac{\alpha \beta}{(\alpha+\beta)^{2}}\left(\alpha r_{1}+r_{2}\right)<r_{2}$. Rearranging each inequality and bringing them together yields the condition $r \in\left(\lim _{x \rightarrow \tau} \underline{r}, \lim _{x \rightarrow \tau} \bar{r}\right)$.

Part 2: Consider first the case when $x \neq \tau$ : Suppose that $b_{1}^{*}=r_{1}$. Then (8) implies

$$
\frac{\partial \tilde{u}_{2}}{\partial b_{2}}\left(r_{1}, b_{2}\right)=\frac{\alpha r_{1}}{\left(\alpha r_{1}+b_{2}\right)^{2}}\left(r_{2}-b_{2}\right)-\frac{b_{2}}{\alpha r_{1}+b_{2}}=0
$$

when

$$
b_{2}=-\alpha r_{1}+\sqrt{\alpha r_{1}\left(r_{2}+\alpha r_{1}\right)}<r_{2} .
$$

So, $b_{2}^{*}$ given by $(16)$ is best response to $b_{1}^{*}=r_{1}$.

Now, suppose that $b_{2}^{*}$ is given by (16). Then it follows from $\frac{\partial^{2} \tilde{u}_{1}\left(b_{1}, b_{2}\right)}{\partial b_{1}^{2}}<0$ that $b_{1}^{*}=r_{1}$ is 
best response if and only if $\frac{\partial \tilde{u}_{1}}{\partial b_{1}}\left(r_{1}, b_{2}^{*}\right)>0$. Using (6), $\frac{\partial \tilde{u}_{1}}{\partial b_{1}}\left(r_{1}, b_{2}^{*}\right)>0$ can be rewritten as $-\beta(1-x)-\beta x\left[\frac{\alpha r_{1}}{\sqrt{\alpha r_{1}\left(\alpha r_{1}+r_{2}\right)}}\right]+\frac{\left[\sqrt{\alpha r_{1}\left(\alpha r_{1}+r_{2}\right)}-\alpha r_{1}\right]\left\{r_{2}-\left[\sqrt{\alpha r_{1}\left(\alpha r_{1}+r_{2}\right)}-\alpha r_{1}\right]\right\}}{r_{1}\left(\alpha r_{1}+r_{2}\right)}>0$

which can be simplified to

$$
(2 x-4 \tau-1) \tau(\beta r)^{2}+\left[2 x \tau-4 \tau-(1-x)^{2}\right](\beta r)+\tau>0
$$

This latter condition can be shown to hold whenever $r<\underline{r}$. The proof for the case when $x=\tau$ follows along similar lines.

Part 3: Consider the case when $x \neq \tau$. Suppose that $b_{2}^{*}=r_{2}$. Then, (6) implies

$$
\frac{\partial \tilde{u}_{1}}{\partial b_{1}}\left(b_{1}, r_{2}\right)=-\beta(1-x)-\beta x\left(\frac{\alpha b_{1}}{\alpha b_{1}+r_{2}}\right)+\frac{\alpha r_{2}}{\left(\alpha b_{1}+r_{2}\right)^{2}} x \beta\left(r_{1}-b_{1}\right)=0
$$

when

$$
b_{1}=\frac{1}{\alpha}\left[\sqrt{x r_{2}\left(\alpha r_{1}+r_{2}\right)}-r_{2}\right]<r_{1}
$$

So, $b_{1}^{*}$ given by $(17)$ is best response to $b_{2}^{*}=r_{2}$.

Now, suppose that $b_{1}^{*}$ is given by (17). Then it follows from $\frac{\partial^{2} \tilde{u}_{2}\left(b_{1}, b_{2}\right)}{\partial b_{2}^{2}}<0$ that $b_{2}^{*}=r_{2}$ is best response if and only if $\frac{\partial \tilde{u}_{2}}{\partial b_{2}}\left(b_{1}, r_{2}\right)>0$. Using (8), $\frac{\partial \tilde{u}_{2}}{\partial b_{2}}\left(b_{1}, r_{2}\right)>0$ can be rewritten as

$$
\left[\sqrt{x r_{2}\left(\alpha r_{1}+r_{2}\right)}-r_{2}\right] x \beta\left\{r_{1}-\frac{1}{\alpha}\left[\sqrt{x r_{2}\left(\alpha r_{1}+r_{2}\right)}-r_{2}\right]\right\}-r_{2} \sqrt{x r_{2}\left(\alpha r_{1}+r_{2}\right)}>0
$$

which can be simplified to

$$
(\beta r)^{2} x \tau-(\beta r)\left(2 \tau+(1-x)^{2}\right)+\frac{\tau}{x}-\frac{1}{\tau}(1-x)^{2}-4>0
$$

This latter condition can be shown to hold whenever $r>\bar{r}$. The proof for the case when $x=\tau$ follows along similar lines. 
Proof of Proposition 1: Suppose condition $r>\left.\underline{r}\right|_{x=0}$ holds. The partial derivatives with respect to $\alpha$ are $\frac{\partial b_{1}^{*}}{\partial \alpha}=\frac{r_{2}}{2 \alpha^{2}}(4 \tau+1)^{-\frac{3}{2}}\left[(4 \tau+1)^{\frac{3}{2}}-\left(4 \tau^{2}+6 \tau+1\right)\right]$, which is positive if and only if $\tau \lesssim 1.2071 ; \frac{\partial b_{2}^{*}}{\partial \alpha}=\frac{r_{2}}{\beta(4 \tau+1)^{\frac{3}{2}}}$, which is positive; and $\frac{\partial p^{*}}{\partial \alpha}=\frac{1}{\alpha} \frac{2 \tau+1-\sqrt{4 \tau+1}}{2 \tau \sqrt{4 \tau+1}}$, which is positive.

Suppose condition $r<\left.\underline{r}\right|_{x=0}$ holds. The partial derivatives with respect to $\alpha$ are $\frac{\partial b_{1}^{*}}{\partial \alpha}=0$; $\frac{\partial b_{2}^{*}}{\partial \alpha}=\frac{r_{1}}{\sqrt{1+\frac{1}{\alpha r}}}\left(1-\sqrt{1+\frac{1}{\alpha r}}+\frac{1}{2 \alpha r}\right)$, which is positive since the term in the parenthesis is decreasing in $\alpha r$ and converges to zero as $\alpha r$ goes to infinity; and $\frac{\partial p^{*}}{\partial \alpha}=\frac{1}{2 \alpha^{2} r\left(1+\frac{1}{\alpha r}\right)^{3 / 2}}$, which is positive.

Proof of Proposition 2: Suppose condition $r>\left.\underline{r}\right|_{x=0}$ holds. The partial derivatives with respect to $\beta$ are $\frac{\partial b_{1}^{*}}{\partial \beta}=-\frac{2 \tau r_{2}}{\beta^{2}(4 \tau+1)^{\frac{3}{2}}}$, which is negative; $\frac{\partial b_{2}^{*}}{\partial \beta}=-\frac{\tau r_{2}}{\beta(4 \tau+1)^{\frac{3}{2}}}$, which is negative; and $\frac{\partial p^{*}}{\partial \beta}=-\frac{2 \tau+1-\sqrt{4 \tau+1}}{2 \alpha \sqrt{4 \tau+1}}$, which is negative.

Suppose condition $r<\left.\underline{r}\right|_{x=0}$ holds. Since $b_{1}^{*}, b_{2}^{*}$ and $p^{*}$ are all independent of $\beta$, the result immediately follows.

Proof of Proposition 3: Suppose condition $r>\left.\underline{r}\right|_{x=0}$ holds. Since $b_{1}^{*}, b_{2}^{*}$ and $p^{*}$ are all independent of $r_{1}$, an increase in $r_{1}$ has no effect on them. Since $p^{*}$ is also independent of $r_{2}$, an increase in $r_{2}$ has no effect on $p^{*}$. Moreover, $b_{1}^{*}$ and $b_{2}^{*}$ are linearly increasing in $r_{2}$.

Suppose condition $r<\left.\underline{r}\right|_{x=0}$ holds. Since $b_{1}^{*}=r_{1}$, it is obvious that $b_{1}^{*}$ increases in $r_{1}$ and is not affected by changes in $r_{2}$. The partial derivatives of $b_{2}^{*}$ with respect to $r_{1}$ and $r_{2}$ are $\frac{\partial b_{2}^{*}}{\partial r_{1}}=\frac{\alpha}{\sqrt{\frac{1}{\alpha r}+1}}\left(\frac{1}{2 \alpha r}+1-\sqrt{\frac{1}{\alpha r}+1}\right)$, which is positive since the term in the parenthesis is decreasing in $\alpha r$ and converges to zero as $\alpha r$ goes to infinity; and $\frac{\partial b_{2}^{*}}{\partial r_{2}}=\frac{1}{2 \sqrt{\frac{1}{\alpha r}+1}}>0$, respectively. Finally, $p^{*}=\frac{1}{\sqrt{1+\frac{1}{\alpha r}}}$ increases in $r$. Hence, $p^{*}$ is increasing in $r_{1}$ and decreasing in $r_{2}$.

Proof of Proposition 4: Observe that $\left.\underline{r}\right|_{x=0}<\left.\underline{r}\right|_{x=1}<\left.\bar{r}\right|_{x=1}$. This inequality and Corollaries 1 and 2 allow splitting the parameter space into three different ranges satisfying $r>\left.\underline{r}\right|_{x=0}$. We show that $b_{1}^{*}$ is no larger when $x=0$ than when $x=1$ in any of these three ranges.

First, suppose $r \in\left(\left.\underline{r}\right|_{x=0},\left.\underline{r}\right|_{x=1},\right)$. Then it follows from Corollaries 1 and 2 that $b_{1}^{*}=r_{1}$ 
when $x=1$, but $b_{1}^{*}<r_{1}$ when $x=0$. Moreover, it follows from Corollaries 1 and 2 that $b_{2}^{*}$ is smaller when $x=0$ than when $x=1$ if and only if

$$
1-\frac{1}{\sqrt{4 \tau+1}}<2 \alpha r\left(\sqrt{1+\frac{1}{\alpha r}}-1\right)
$$

The left-hand side is independent of $r$. The right-hand side is increasing in $r$, such that its lowest value within the feasible range is attained at $r=\left.\underline{r}\right|_{x=0}=\frac{1}{2 \alpha}\left(\frac{2 \tau+1}{\sqrt{4 \tau+1}}-1\right)$. This value is $1-\frac{1}{\sqrt{4 \tau+1}}$. Hence $b_{2}^{*}$ is indeed smaller when $x=0$ than when $x=1$ if $r \in\left(\left.\underline{r}\right|_{x=0},\left.\underline{r}\right|_{x=1}\right)$.

Second, suppose $r \in\left(\left.\underline{r}\right|_{x=1},\left.\bar{r}\right|_{x=1}\right)$. Then it follows from Corollaries 1 and 2 that $b_{1}^{*}$ is smaller when $x=0$ than when $x=1$ if and only if

$$
r_{2}\left(\frac{2 \tau+1}{\sqrt{4 \tau+1}}-1\right)<\left(\beta r_{1}+r_{2}\right) \frac{\tau}{\sqrt{\tau}+1} \Leftrightarrow r>\frac{1}{\beta}\left[\left(\frac{2 \tau+1}{\sqrt{4 \tau+1}}-1\right)\left(\frac{\sqrt{\tau}+1}{\tau}\right)-1\right]
$$

Since the smallest possible value of $r$ in this range is $\left.\underline{r}\right|_{x=1}=\frac{1}{\beta(2 \sqrt{\tau}+1)}$, we need to show that

$$
\frac{1}{\beta(2 \sqrt{\tau}+1)}>\frac{1}{\beta}\left[\left(\frac{2 \tau+1}{\sqrt{4 \tau+1}}-1\right)\left(\frac{\sqrt{\tau}+1}{\tau}\right)-1\right] \Leftrightarrow-4 \tau\left(4 \tau+2 \sqrt{\tau}+4 \tau^{\frac{3}{2}}+1\right)<0,
$$

which holds for all $\tau>0$. Moreover, it follows from Corollaries 1 and 2 that $b_{2}^{*}$ is smaller when $x=0$ than when $x=1$ if and only if

$$
r_{2}\left(1-\frac{1}{\sqrt{4 \tau+1}}\right)<\left(\beta r_{1}+r_{2}\right) \frac{\sqrt{\tau}}{\sqrt{\tau}+1} \Leftrightarrow r>\frac{1}{\beta}\left[\left(1-\frac{1}{\sqrt{4 \tau+1}}\right) \frac{\sqrt{\tau}+1}{\sqrt{\tau}}-1\right]
$$

Since the smallest possible value of $r$ in this range is $\left.\underline{r}\right|_{x=1}=\frac{1}{\beta(2 \sqrt{\tau}+1)}$, we need to show that

$$
\frac{1}{\beta(2 \sqrt{\tau}+1)}>\frac{1}{\beta}\left[\left(1-\frac{1}{\sqrt{4 \tau+1}}\right) \frac{\sqrt{\tau}+1}{\sqrt{\tau}}-1\right] \Leftrightarrow 2 \sqrt{\tau}-\sqrt{4 \tau+1}+1>0,
$$

which holds for all $\tau>0$. (To see this note that the left-hand side is increasing in $\tau$.)

Finally, suppose $r>\left.\bar{r}\right|_{x=1}$. Then it follows from Corollaries 1 and 2 that $b_{1}^{*}$ is smaller 
when $x=0$ than when $x=1$ if and only if

$$
\frac{1}{2}\left(\frac{2 \tau+1}{\sqrt{4 \tau+1}}-1\right)<\sqrt{\alpha r+1}-1 \Leftrightarrow r>\frac{1}{\alpha}\left[\left(\frac{2 \tau+1+\sqrt{4 \tau+1}}{2 \sqrt{4 \tau+1}}\right)^{2}-1\right]
$$

Since the smallest possible value of $r$ in this range is $\left.\bar{r}\right|_{x=1}=\frac{1}{\beta}\left(\frac{2}{\sqrt{\tau}}+1\right)$, we need to show that

$$
\begin{array}{r}
\frac{1}{\beta}\left(\frac{2}{\sqrt{\tau}}+1\right)>\frac{1}{\alpha}\left[\left(\frac{2 \tau+1+\sqrt{4 \tau+1}}{2 \sqrt{4 \tau+1}}\right)^{2}-1\right] \\
\Leftrightarrow-\frac{1}{8 \tau+2}\left(6 \tau-\sqrt{4 \tau+1}+6 \tau^{2}+4 \sqrt{\tau}+16 \tau^{\frac{3}{2}}-2 \tau \sqrt{4 \tau+1}+1\right)<0,
\end{array}
$$

which holds for all $\tau>0$. Moreover, it follows from Corollaries 1 and 2 that $b_{2}^{*}=r_{2}$ when $x=1$, but $b_{2}^{*}<r_{2}$ when $x=0$.

Proof of Proposition 5: We proceed as in the proofs of Propositions 4, and show that $p^{*}$ is no larger when $x=0$ than when $x=1$ in any of the three ranges of the parameter space satisfying $r>\left.\underline{r}\right|_{x=0}$.

First, suppose $r \in\left(\left.\underline{r}\right|_{x=0},\left.\underline{r}\right|_{x=1}\right)$. Then it follows from Corollaries 1 and 2 that $p^{*}$ is smaller when $x=0$ than when $x=1$ if and only if

$$
1-\frac{\sqrt{4 \tau+1}-1}{2 \tau}<\frac{1}{\sqrt{1+\frac{1}{\alpha r}}} \Leftrightarrow r>\frac{1}{2 \alpha}\left(\frac{2 \tau+1}{\sqrt{4 \tau+1}}-1\right)=\left.\underline{r}\right|_{x=0},
$$

which holds by assumption if $r \in\left(\left.\underline{r}\right|_{x=0},\left.\underline{r}\right|_{x=1}\right)$.

Second, suppose $r \in\left(\left.\underline{r}\right|_{x=1},\left.\bar{r}\right|_{x=1}\right)$. Then it follows from Corollaries 1 and 2 that $p^{*}$ is smaller when $x=0$ than when $x=1$ if and only if

$$
1-\frac{\sqrt{4 \tau+1}-1}{2 \tau}<\frac{\sqrt{\tau}}{\sqrt{\tau}+1} \Leftrightarrow 2 \tau+1<(\sqrt{\tau}+1) \sqrt{4 \tau+1}-\sqrt{\tau}
$$

which is true for any $\tau>0$. 
Finally, suppose $r>\left.\bar{r}\right|_{x=1}$. Then it follows from Corollaries 1 and 2 that $p^{*}$ is smaller when $x=0$ than when $x=1$ if and only if

$$
1-\frac{\sqrt{4 \tau+1}-1}{2 \tau}<1-\frac{1}{\sqrt{\alpha r+1}} \Leftrightarrow r>\frac{1}{\alpha}\left[\frac{4 \tau^{2}}{(\sqrt{4 \tau+1}-1)^{2}}-1\right]
$$

which is true whenever $r>\frac{1}{\beta}\left(\frac{2}{\sqrt{\tau}}+1\right)=\left.\bar{r}\right|_{x=1}$.

Proof of Proposition 6: We start by stating the players' equilibrium expected payoffs given $x=0$ and $x=1$. First, suppose that $x=0$, then their equilibrium expected payoffs are given by

$$
\begin{aligned}
& \left.\tilde{u}_{1}\left(b_{1}^{*}, b_{2}^{*}\right)\right|_{x=0}= \begin{cases}\beta r_{1}+\frac{r_{2}}{2}\left(\frac{1}{\tau}+1-\frac{3+\frac{1}{\tau}}{\sqrt{4 \tau+1}}\right) & \text { if } r>\left.\underline{r}\right|_{x=0} \\
\alpha r_{1}\left(\sqrt{1+\frac{1}{\alpha r}}-1\right) & \text { if } r<\left.\underline{r}\right|_{x=0}\end{cases} \\
& \left.\tilde{u}_{2}\left(b_{1}^{*}, b_{2}^{*}\right)\right|_{x=0}= \begin{cases}\frac{r_{2}}{\sqrt{4 \tau+1}} & \text { if } r>\left.\underline{r}\right|_{x=0} \\
r_{2}-2 \alpha r_{1}\left(\sqrt{1+\frac{1}{\alpha r}}-1\right) & \text { if } r<\left.\underline{r}\right|_{x=0}\end{cases}
\end{aligned}
$$

Second, suppose that $x=1$, then their equilibrium expected payoffs are given by

$$
\begin{aligned}
& \left.\tilde{u}_{1}\left(b_{1}^{*}, b_{2}^{*}\right)\right|_{x=1}= \begin{cases}\frac{r_{2}}{\tau}(\sqrt{\alpha r+1}-1)^{2} & \text { if } r>\left.\bar{r}\right|_{x=1} \\
\frac{\sqrt{\tau}}{\sqrt{\tau}+1} \frac{\beta r_{1}+r_{2}}{2} & \text { if } r \in\left(\left.\underline{r}\right|_{x=1},\left.\bar{r}\right|_{x=1}\right) \\
\alpha r_{1}\left(\sqrt{1+\frac{1}{\alpha r}}-1\right) & \text { if } r<\left.\underline{r}\right|_{x=1}\end{cases} \\
& \left.\tilde{u}_{2}\left(b_{1}^{*}, b_{2}^{*}\right)\right|_{x=1}= \begin{cases}\frac{r_{2}}{\tau}(\sqrt{\alpha r+1}-1) & \text { if } r>\left.\bar{r}\right|_{x=1} \\
\frac{1}{\sqrt{\tau}+1} \frac{\beta r_{1}+r_{2}}{2} & \text { if } r \in\left(\left.\underline{r}\right|_{x=1},\left.\bar{r}\right|_{x=1}\right) \\
r_{2}-2 \alpha r_{1}\left(\sqrt{1+\frac{1}{\alpha r}}-1\right) & \text { if } r<\left.\underline{r}\right|_{x=1}\end{cases}
\end{aligned}
$$

We now focus on player 1 and show that $\left.\tilde{u}_{1}\left(b_{1}^{*}, b_{2}^{*}\right)\right|_{x=0}>\left.\tilde{u}_{1}\left(b_{1}^{*}, b_{2}^{*}\right)\right|_{x=1}$ holds in any of the three ranges of the parameter space satisfying $r>\left.\underline{r}\right|_{x=0}$. First, suppose $r \in\left(\left.\underline{r}\right|_{x=0},\left.\underline{r}\right|_{x=1}\right)$. 
In this case, $\left.\tilde{u}_{1}\left(b_{1}^{*}, b_{2}^{*}\right)\right|_{x=0}>\left.\tilde{u}_{1}\left(b_{1}^{*}, b_{2}^{*}\right)\right|_{x=1}$ can be rewritten as

$$
\alpha r\left[1-\tau\left(\sqrt{1+\frac{1}{\alpha r}}-1\right)\right]+\frac{1}{2}\left(1+\tau-\frac{3 \tau+1}{\sqrt{4 \tau+1}}\right)>0 .
$$

This inequality holds for all $r \in\left(\left.\underline{r}\right|_{x=0},\left.\underline{r}\right|_{x=1}\right)$ because its left-hand side is increasing in $\alpha r$ and

$$
\lim _{\left.r \rightarrow \underline{r}\right|_{x=0}} \alpha r\left[1-\tau\left(\sqrt{1+\frac{1}{\alpha r}}-1\right)\right]=-\frac{1}{2}\left(1+\tau-\frac{3 \tau+1}{\sqrt{4 \tau+1}}\right) .
$$

Second, suppose $r \in\left(\left.\underline{r}\right|_{x=1},\left.\bar{r}\right|_{x=1}\right)$, which implies $\frac{\tau}{2 \sqrt{\tau}+1}<\alpha r<\tau\left(\frac{2}{\sqrt{\tau}}+1\right)$. In this case, $\left.\tilde{u}_{1}\left(b_{1}^{*}, b_{2}^{*}\right)\right|_{x=0}>\left.\tilde{u}_{1}\left(b_{1}^{*}, b_{2}^{*}\right)\right|_{x=1}$ can be rewritten as

$$
\alpha r>\frac{\left(\frac{\tau \sqrt{\tau}}{\sqrt{\tau}+1}+\frac{3 \tau+1}{\sqrt{4 \tau+1}}-(1+\tau)\right)}{\left(\frac{\sqrt{\tau}+2}{\sqrt{\tau}+1}\right)} .
$$

The smallest value of $\alpha r$ in the feasible range is $\frac{\tau}{2 \sqrt{\tau}+1}$. So, the above inequality holds in the feasible range if

$$
\frac{\tau}{2 \sqrt{\tau}+1}>\frac{\left(\frac{\tau \sqrt{\tau}}{\sqrt{\tau}+1}+\frac{3 \tau+1}{\sqrt{4 \tau+1}}-(1+\tau)\right)}{\left(\frac{\sqrt{\tau}+2}{\sqrt{\tau}+1}\right)}
$$

This latter inequality can be shown to be equivalent to $4 \tau+16 \tau^{2}+4 \tau^{\frac{3}{2}}+12 \tau^{\frac{5}{2}}>0$, which is always true.

Third, suppose $r>\left.\bar{r}\right|_{x=1}$, which implies $\alpha r>\tau\left(\frac{2}{\sqrt{\tau}}+1\right)$. In this case, $\left.\tilde{u}_{1}\left(b_{1}^{*}, b_{2}^{*}\right)\right|_{x=0}>$ $\left.\tilde{u}_{1}\left(b_{1}^{*}, b_{2}^{*}\right)\right|_{x=1}$ can be rewritten as

$$
1+\tau-\frac{3 \tau+1}{\sqrt{4 \tau+1}}>4(1-\sqrt{\alpha r+1})
$$

The right-hand side of the above inequality is decreasing in $\alpha r$. Hence, it is enough to show that the inequality holds for $\alpha r=\tau\left(\frac{2}{\sqrt{\tau}}+1\right)$. Inserting $\alpha r=\tau\left(\frac{2}{\sqrt{\tau}}+1\right)$ allows rewriting the above inequality as

$$
1+\tau-\frac{3 \tau+1}{\sqrt{4 \tau+1}}>-4 \sqrt{\tau} .
$$


This inequality always holds since the left-hand side is positive and the right-hand side negative for $\tau>0$.

We now turn to player 2. We again look separately at the three ranges of the parameter space satisfying $r>\left.\underline{r}\right|_{x=0}$. First, suppose $r \in\left(\left.\underline{r}\right|_{x=0},\left.\underline{r}\right|_{x=1}\right)$. In this case, $\left.\tilde{u}_{2}\left(b_{1}^{*}, b_{2}^{*}\right)\right|_{x=0}>$ $\left.\tilde{u}_{2}\left(b_{1}^{*}, b_{2}^{*}\right)\right|_{x=1}$ can be rewritten as

$$
\frac{1}{\sqrt{4 \tau+1}}>1-2 \alpha r\left(\sqrt{1+\frac{1}{\alpha r}}-1\right) .
$$

Note that the right-hand side is decreasing in $\alpha r$, and that the right-hand side converges to left-hand side as $r$ converges to $\left.\underline{r}\right|_{x=0}$. Hence, this inequality holds in the feasible range. Therefore, player 2 prefers asymmetric warfare over symmetric warfare whenever $r \in\left(\left.\underline{r}\right|_{x=0},\left.\underline{r}\right|_{x=1}\right)$.

Second, suppose $r \in\left(\left.\underline{r}\right|_{x=1},\left.\bar{r}\right|_{x=1}\right)$. In this case, $\left.\tilde{u}_{2}\left(b_{1}^{*}, b_{2}^{*}\right)\right|_{x=0}>\left.\tilde{u}_{2}\left(b_{1}^{*}, b_{2}^{*}\right)\right|_{x=1}$ can be rewritten as $r<\rho$. Therefore, player 2 prefers asymmetric warfare over symmetric warfare whenever $r \in\left(\left.\underline{r}\right|_{x=1}, \rho\right)$, and symmetric warfare over asymmetric warfare whenever $r \in$ $\left(\rho,\left.\bar{r}\right|_{x=1}\right)$.

Finally, suppose $r>\left.\bar{r}\right|_{x=1}$, which implies $\alpha r>\tau\left(\frac{2}{\sqrt{\tau}}+1\right)$. In this case, $\left.\tilde{u}_{2}\left(b_{1}^{*}, b_{2}^{*}\right)\right|_{x=0}<$ $\left.\tilde{u}_{2}\left(b_{1}^{*}, b_{2}^{*}\right)\right|_{x=1}$ can be rewritten as

$$
\alpha r>\left(\frac{\tau}{\sqrt{4 \tau+1}}+1\right)^{2}-1
$$

This inequality holds in the feasible range because

$$
\tau\left(\frac{2}{\sqrt{\tau}}+1\right)>\left(\frac{\tau}{\sqrt{4 \tau+1}}+1\right)^{2}-1
$$

reduces to $\tau\left(29 \tau+54 \tau^{2}+9 \tau^{3}+4 \sqrt{\tau}+28 \tau^{\frac{3}{2}}+48 \tau^{\frac{5}{2}}+4\right)>0$, which is always true. Therefore, player 2 prefers symmetric warfare over asymmetric warfare whenever $r>\left.\bar{r}\right|_{x=1}$. 


\section{References}

[1] Arce, D.G., D. Kovenock, and B. Roberson (2012). Weakest-link attacker-defender games with multiple attack technologies. Naval Research Logistics 59, 457-469.

[2] Bester, H., and K.A. Konrad (2004). Delay in contests. European Economic Review 48, 1169-1178.

[3] Blattman, C., and E. Miguel (2010). Civil war. Journal of Economic Literature 48, 3-57.

[4] Clark, D.J., and K.A. Konrad (2007). Asymmetric conflict: Weakest link against best shot. Journal of Conflict Resolution 51, 457-469.

[5] Franke, J., C. Kanzow, W. Leininger, and A. Schwartz (2013). Effort maximization in asymmetric contest games with heterogeneous contestants. Economic Theory 52, 589630.

[6] Garfinkel, M.R. (1990). Arming as a strategic investment in a cooperative equilibrium. American Economic Review 80, 50-68.

[7] Garfinkel, M.R., and S. Skaperdas (2007). Economics of Conflict: An Overview. In: T. Sandler and K. Hartley (eds.), Handbook of Defence Economics (vol. 2). North-Holland, Amsterdam.

[8] Grossman, H.I. (1991). A general equilibrium model of insurrections. American Economic Review 81, 912-921.

[9] Grossman, H.I., and M. Kim (1995). Swords or plowshares? A theory of the security of claims to property. Journal of Political Economy 103, 1275-288.

[10] Grossman, H.I., and M. Kim (1996). Predation and Production. In: M.R. Garfinkel and S. Skaperdas (eds.), The Political Economy of Conflict and Appropriation, Cambridge University Press, Cambridge. 
[11] Haavelmo, T. (1954). A Study in the Theory of Economic Evolution. North-Holland, Amsterdam.

[12] Hillman, A.L., and J.G. Riley (1989). Politically contestable rents and transfers. Economics and Politics 1, 17-39.

[13] Hirshleifer, J. (1991). The paradox of power. Economics and Politics 3, 177-200.

[14] Hirshleifer, J. (2001). The Dark Side of the Force: Economic Foundations of Conflict Theory. Cambridge University Press, Cambridge.

[15] Hoffmann, M., and G. Rota-Graziosi (2012). Endogenous timing in general rent-seeking and conflict models. Games and Economic Behavior 75, 168-184.

[16] Kolmar, M. (2008). Perfectly secure property rights and production inefficiencies in Tullock contests. Southern Economic Journal 75, 441-456.

[17] Konrad, K.A. (2009). Strategy and Dynamics in Contests, Oxford University Press, Oxford.

[18] Nti, K.O. (1999). Rent-seeking with asymmetric valuations. Public Choice 98, 415-430.

[19] Powell, R. (2007a). Defending against terrorist attacks with limited resources. American Political Science Review 101, 527-541.

[20] Powell, R. (2007b). Allocating defensive resources with private information about vulnerability. American Political Science Review 101, 799-809.

[21] Shubik, M., and R. Weber (1981). Systems defense games: Colonel Blotto, command and control. Naval Research Logistics Quarterly 28, 281-287.

[22] Skaperdas, S. (1992). Cooperation, conflict, and power in the absence of property rights. American Economic Review 82, 720-739. 
[23] Tullock, G. (1980). Efficient rent seeking, in: J.M. Buchanan, R.D. Tollison, and G. Tullock (eds.), Toward a Theory of the Rent Seeking Society, Texas A\&M University Press, College Station.

[24] Wärneryd, K. (2003). Information in conflicts. Journal of Economic Theory 110, 121-136. 


\section{Figures}
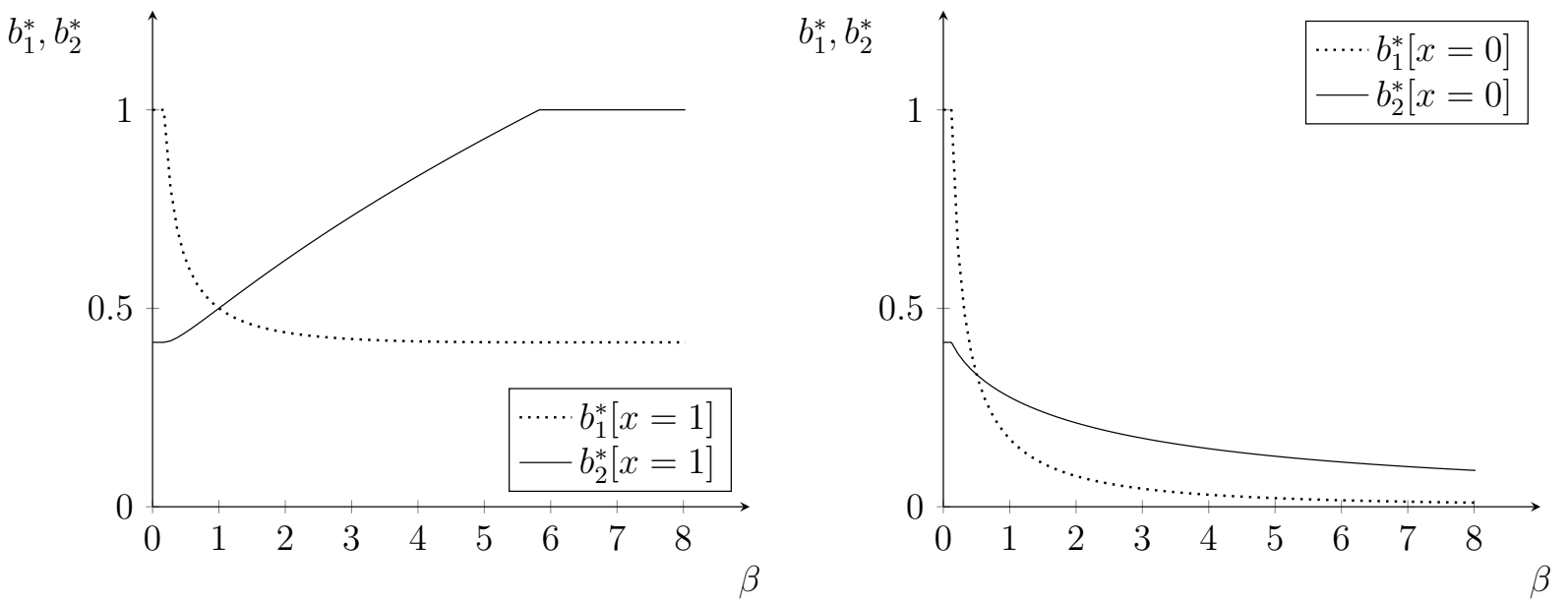

Figure 1: Equilibrium strategies for different values of $\beta$ in symmetric wars $(x=1$, left panel) and asymmetric wars $(x=0$, right panel) given $\alpha=1$ and $r=1$ 